\title{
Effervescent atomization of viscous liquids
}

\author{
Vignesh Kumar $\mathrm{D}^{* 1}$, Anand T N C ${ }^{2,3}$, Madan Mohan Avulapati ${ }^{1}$ \\ ${ }^{1}$ Mechanical Engineering, Indian Institute of Technology Tirupati, Tirupati, India \\ ${ }^{2}$ Mechanical Engineering, Indian Institute of Technology Madras, Chennai, India \\ ${ }^{3}$ Mechanical Engineering, Indian Institute of Technology Palakkad, Palakkad, India \\ ${ }^{*}$ Corresponding author email: me19d509@iittp.ac.in
}

\begin{abstract}
The study of high viscosity liquid atomization is of interest especially in agricultural food processing and pharmaceutical industries, where the viscosity of the liquid increases with an increase in the dry matter content. Effervescent atomizer is one kind of twin-fluid atomizer used for effective atomization of high viscosity liquids. The present study focuses on correlating internal two-phase flow characteristics of an effervescent atomizer with the external spray characteristics. Spray structure images covering a distance of $80 \mathrm{~mm}$ downstream of the exit orifice, and images of the entire two-phase flow mixing region were captured by diffuse backlit imaging using a high-speed camera. The spray cone angle was estimated at different gas-to-liquid ratios (GLRs), when operated at a liquid injection pressure of $0.5 \pm 0.01 \mathrm{MPa}$. Spray unsteadiness was studied by estimating the variation in the moving average of the spray cone angle (taken over 50 images). The study shows that the internal two-phase flow governs the external spray characteristics in effervescent atomization. Annular flow regime formed at higher GLRs gives a stable spray while slug flow regimes formed at reduced GLRs leads to a larger variation in spray structure. Though the bubbly flow regime for higher viscosity liquid shows smaller variation in spray cone angle, the atomization was observed to be inferior with an intact liquid jet.
\end{abstract}

\section{Keywords}

Effervescent atomization, Twin-fluid atomizer, Internal flow, Spray characteristics

\section{Introduction}

Spray drying is a widely used particle production technology in food, pharmaceutical, ceramic, chemical and polymer industries [1]. One way to increase the efficiency of the spray drying process is to decrease the energy consumed for heating and evaporation in the drying chamber. This can be done by decreasing the amount of moisture content of the liquid feed. In most of the liquids, a decrease in moisture content increases the viscosity of the liquid, which also increases the size of the droplets and also leads to a wider drop size distribution during atomization. Eventually, this may result in the formation of wet powder and will pose difficulties during powder recovery at the collection chamber [2]. Hence it is necessary to use an atomiser which can effectively convert viscous liquid feed into small droplets with an optimum droplet size distribution.

The most commonly used atomizers in the spray drying process are rotary atomizers, pressure atomizers and twin fluid atomizers [3,4]. Rotary atomizers face difficulties in atomizing high viscosity liquids [3,5]. Also, due to its centrifugal spraying action, it poses difficulty in accommodating it in horizontal spray dryers [3]. Pressure atomizers, when utilized with viscous liquids, produce larger droplets compared to rotary and twin fluid atomizers [3,5]. Twin fluid atomizers typically use gas energy to break the liquid into droplets. Effervescent atomizer is a type of twin fluid atomizer which can work with less amount of gas energy and can also produce smaller liquid droplets [5,6]. The effervescent atomizer consists of a mixing chamber through which a small amount of gas is injected to form a two-phase flow. When this twophase flow comes out of the exit orifice, there will be a sudden pressure drop and the gas 
phase expands, shattering the liquid phase into ligaments and droplets. A mean droplet size of the order of $25 \mu \mathrm{m}$ could be achieved even after working with fluids of viscosity of the order of $400 \mathrm{mPa}-\mathrm{s}$ [7]. A problem encountered in an effervescent atomizer is its spray unsteadiness, which is generally attributed to the character of the two phase flow in the atomizer [6,8-16]. The two phase flow pattern depends mainly upon the gas-to-liquid ratio (GLR) [6,8-17]. At very low GLRs, gas is injected as bubbles inside the mixing chamber resulting in a bubbly flow regime. On increasing the GLR, the bubbles coalesce to become slugs, resulting in a slug flow regime. On further increasing the GLR, an annular flow regime is formed, in which liquid is attached to the wall surface while gas occupies the central core region. Avulapati and Ravikrishna [8] observed the two-phase flow inside the exit orifice and found that at low GLRs, the flow structure is highly transient and all the three regimes were found to occur intermittently. Stahle et al. $[9,16]$ also observed the same phenomenon of transient flow regime inside the exit orifice.

In the present study, an attempt was made to correlate the transient nature of the two-phase flow regime inside the atomizer with the external spray characteristics, at different liquid viscosities and GLRs. An effervescent atomizer made of acrylic material was designed and fabricated to visualize and capture the two-phase flow pattern inside the atomization chamber. The spray unsteadiness can be characterised by finding the variation in either the mean droplet size [9,14-16] or spray cone angle [8], as a function of time. In our present study, the variation of spray cone angle was used to determine the spray unsteadiness. To understand the effect of viscosity, two compositions of glycerol-water mixtures were studied at different GLRs.

\section{Experimental setup and Methodology}

The experimental setup used in the study consists of three major subsystems viz. 1) Flow control arrangement 2) Atomizer and 3) Spray Visualization chamber. Gas and liquid supply to the atomizer was maintained at a desirable pressure and flow rate with the help of a flow control arrangement, as shown in Figure 1. Compressed gas from a high-pressure cylinder was used to pressurize the liquid accumulator, which can be safely operated up to a pressure of $3 \mathrm{MPa}$. A pressure relief valve was fitted to the accumulator to protect the system in case of an over-pressure event. Pressure regulators were used to regulate the pressure of gas and liquid in the flow lines. A mass flow controller measured and controlled the amount of gas injected. A needle valve was used to control the flow rate of liquid, and a liquid flow meter with oval rotors was used for measuring the flow rate of liquid. Solenoid flow control valves and pressure transducers were placed close to the exit in both liquid and gas flow lines for measuring the injection pressure. The output readings from the pressure transducer were acquired through the communication interface of the PLC unit.
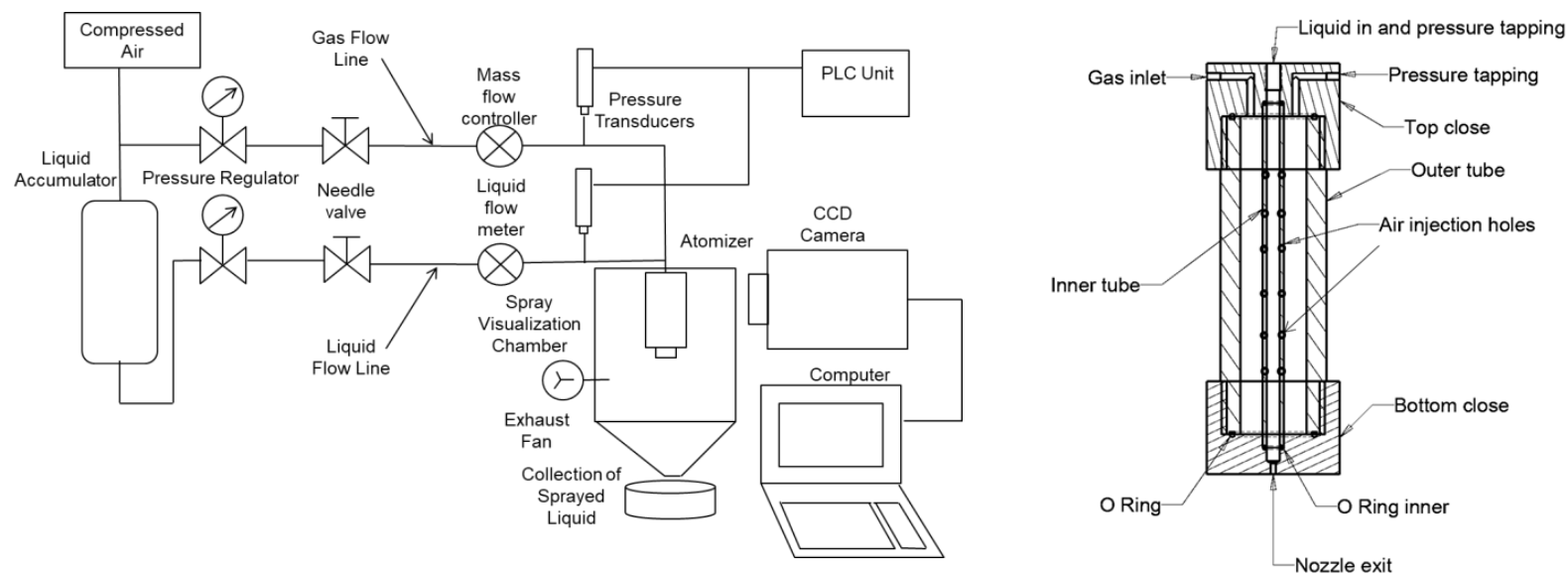

Figure 1. Schematic diagram of the experimental setup and the effervescent atomizer used for the study 
The effervescent atomizer was fixed on the spray visualization chamber which had transparent windows for capturing backlit images. An exhaust fan fixed near the bottom of the chamber collected the mist formed during spraying and avoided the recirculation of droplets, without affecting the spray visualization. For the present study, an effervescent atomizer of 'outsidein' configuration was used. The inner tube, outer tube and the bottom tube that contains the orifice were made with acrylic to provide optical access for observing the two-phase flow regime inside the mixing chamber and near the exit orifice. The inner tube used for the present study has an inner diameter of $6.3 \mathrm{~mm}$ with 12 number of gas injection holes of $0.8 \mathrm{~mm}$ diameter each. The injection holes were placed in 6 rows, diametrically opposite to one another as shown in Figure 1. The gas injection holes are placed at an interval of $15 \mathrm{~mm}$ and the mixing chamber length was kept at $33 \mathrm{~mm}$. The diameter of the exit orifice was kept at 1 $\mathrm{mm}$ and Length to Diameter (L/D) ratio of the exit orifice was 5.85 .

Images of the external spray structure and the internal two-phase flow structure of the atomizer were captured at various conditions by backlit imaging with the help of a CMOS high speed camera. A frame rate of $22500 \mathrm{fps}$ at a resolution of $768 \times 768$ pixels was used to study the dynamics of both internal flow and external spray characteristics. The spray structure images were captured covering a distance upto $80 \mathrm{~mm}$ downstream of the exit orifice. Two phase flow images captured covered the entire region of the mixing chamber. The spray cone angle was estimated at different GLRs using a Matlab-based image processing algorithm. A constant liquid injection pressure of $0.5 \mathrm{MPa}$ was maintained in all the cases of study.

Spray unsteadiness was studied as the variation in the spray cone angle. It is difficult to accurately demarcate the edges of spray from a high-speed image. Hence, an average over 50 spray images (corresponding to $2.2 \mathrm{~ms}$ ) was done for obtaining each value of spray angle. The spray boundaries were identified, and a straight line was fitted to the end points of the boundary on both sides of the spray up to $60 \mathrm{~mm}$ downstream of the exit orifice. Finally, the spray cone angle was estimated by finding the angle between these two lines and the coefficient of variation of these values was taken to find the measure of unsteadiness.

The effect of viscosity was studied by considering two compositions of an aqueous solution of glycerol. The properties of these two liquids are tabulated in Table 1. From the measured values of properties, it can be observed that the difference in density and surface tension of the two liquids is less than $7 \%$, while the variation in viscosity is one order of magnitude. Hence, viscosity is the main physical property whose change may influence the spray and two-phase characteristics, in this study.

Table 1 - Properties of the aqueous glycerol mixtures used for the present study

\begin{tabular}{c|cccccc}
\hline S.No & $\begin{array}{c}\text { Glycerol } \\
\text { Composition } \\
\text { (in \%) }\end{array}$ & $25^{\circ} \mathrm{C}$ & $30^{\circ} \mathrm{C}$ & $35^{\circ} \mathrm{C}$ & $\begin{array}{c}\text { Density, at } \\
30^{\circ} \mathrm{C}\left(\mathrm{kg} / \mathrm{m}^{3}\right)\end{array}$ & $\begin{array}{c}\text { Surface } \\
\text { tension, at } \\
30^{\circ} \mathrm{C}(\mathrm{N} / \mathrm{m})\end{array}$ \\
\hline 1 & 60 & 9.0 & 7.5 & 6.9 & 1146 & 0.069 \\
2 & 85 & 81.2 & 59.9 & 45.0 & 1215 & 0.065
\end{tabular}

\section{Results and Discussions}

The operating parameters of the present investigation are tabulated in Table 2. The liquid injection pressure was maintained at $0.5 \pm 0.01 \mathrm{MPa}$ for all the operating conditions. Gas mass flow rate was varied with the help of a digital mass flow controller and the maximum liquid flow 
rate obtained at a given gas flow rate was noted for an injection pressure of $0.5 \mathrm{MPa}$. Experiments were carried out at five different GLRs by varying the mass flow rate of the gas and keeping the maximum liquid flow rate achievable for that particular gas flow rate. The spray exited into atmospheric pressure conditions for all the experiments. A linear correlation was used to approximate the change in viscosity with respect to temperature, and the required viscosity values at the operating temperature were found. The spray characterisation experiments for $60: 40$ glycerol water mixture were performed at $31.5 \pm 0.5^{\circ} \mathrm{C}$ and the same for the $85: 15$ glycerol mixture were performed at $36 \pm 1^{\circ} \mathrm{C}$. The corresponding viscosity values were found to be $7.3 \mathrm{mPa}$-s and $42 \mathrm{mPa}$-s respectively.

Table 2 - Operating conditions used in the present study

\begin{tabular}{|c|c|c|c|c|c|c|}
\hline \multirow[t]{2}{*}{ S.No } & \multicolumn{3}{|c|}{ Viscosity, $7.30 \mathrm{mPa}-\mathrm{s}$ at $31.5^{\circ} \mathrm{C}$} & \multicolumn{3}{|c|}{ Viscosity, $42.05 \mathrm{mPa}-\mathrm{s}$ at $36^{\circ} \mathrm{C}$} \\
\hline & $\begin{array}{l}\text { Gas mass flow } \\
\text { rate, } \mathrm{kg} / \mathrm{hr}\end{array}$ & $\begin{array}{c}\text { Liquid mass } \\
\text { flow rate, } \\
\text { kg/hr }\end{array}$ & GLR(\%) & $\begin{array}{c}\text { Gas mass } \\
\text { flow rate, } \\
\text { kg/hr }\end{array}$ & $\begin{array}{c}\text { Liquid mass } \\
\text { flow rate, } \\
\mathrm{kg} / \mathrm{hr}\end{array}$ & $\operatorname{GLR}(\%)$ \\
\hline 1 & 1.8 & 13.64 & 13.20 & 1.8 & 10.45 & 17.23 \\
\hline 2 & 1.3 & 21.09 & 6.17 & 1.3 & 17.37 & 7.48 \\
\hline 3 & 1 & 26.59 & 3.76 & 1 & 22.36 & 4.47 \\
\hline 4 & 0.7 & 33.35 & 2.10 & 0.7 & 28.07 & 2.49 \\
\hline 5 & 0.4 & 42.40 & 0.94 & 0.4 & 35.72 & 1.12 \\
\hline
\end{tabular}

Two phase flow structure inside the mixing chamber: The images of the two-phase flow structure inside the mixing chamber were captured at different GLRs for liquids with two different viscosity values. Figure 2 shows snapshots of the two-phase regime formed for the $7.3 \mathrm{mPa}$-s liquid under different conditions. The injection holes were placed at an interval of $15 \mathrm{~mm}$ as marked on the left of Figure 2. As shown in Figure 2, at a GLR of $13.2 \%$, the twophase flow regime was found to be annular, with the gas forming the core surrounded by the liquid. At this condition, the annular flow regime was found to be invariant with time. However, the liquid-gas interface was found to be oscillating from time to time and some liquid drops were found to be dispersed inside the gas phase. The same phenomenon was previously observed by Stahle et al [9]. In this study it was observed that due to the unsteady liquid interface, there was unsteadiness in the back pressure, which resulted in gas flow fluctuation of the order of $0.04 \mathrm{~kg} / \mathrm{hr}$. Due to the fluctuation of gas flow rate, at some instances, there was formation of a liquid bridge near to the first gas injection hole, and this liquid bridge was found to break within a short time as it moved downstream as shown in Figure 2 (a-c) (here $t=0$ corresponds to the first image considered at a given GLR). When the GLR was reduced to $6.17 \%$, an increase in the thickness of the liquid interface was observed and the two-phase regime was not completely annular. Liquid bridges separating gas regions were found to occur more frequently compared to those at a GLR of $13.2 \%$, as shown in Figure 2 (d-f).

When the GLR is further decreased to $3.76 \%$, liquid bridges occurred more frequently resulting in the formation of gas slugs. These slugs grew in number and then collapsed to form an annular flow regime as shown in Figure 2(g-i) and this phenomenon was found to repeat. It can be noted that both the slug flow regime and annular flow regime were observed to occur at the same GLR at different times. At a GLR of $2.1 \%$, the slug flow regime was found to occur at all the times of observation. However, the number and size of slugs were found to vary continuously at different times, as shown in Figure 2(j-k). When the GLR was further reduced to $0.94 \%$, a bubbly flow regime was found to occur as shown in Figure $2(\mathrm{I}-\mathrm{m})$. However, at a few instances, the gas bubbles coalesced into a slug which. These slugs were smaller than those observed at the previous GLRs. Also, it was found that at the last pair of injection holes, droplets are ejected from time to time as shown in Figure $2(\mathrm{~m})$. This liquid ejection behaviour 
can be attributed to 1) Low GLR i.e., high liquid flow rate, and 2) the gas velocity $(2.72 \mathrm{~m} / \mathrm{s})$ being closer to the liquid velocity of $0.33 \mathrm{~m} / \mathrm{s}$ and the loss of momentum of the gas phase as it moves downstream towards the orifice.

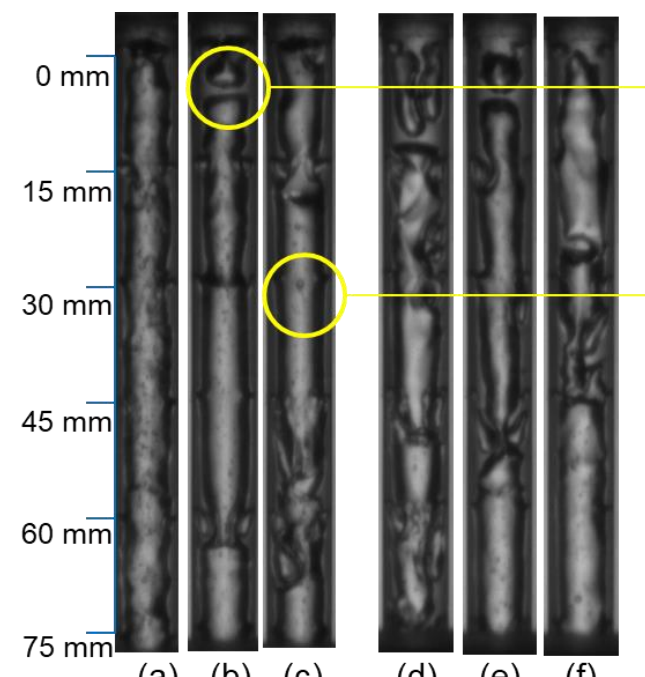

(a) (b) (c)

(d)

(e) (f)

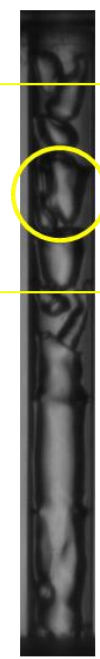

(g)

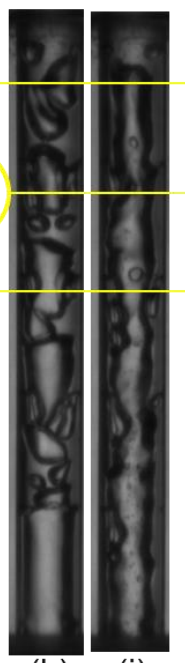

(h) (i)

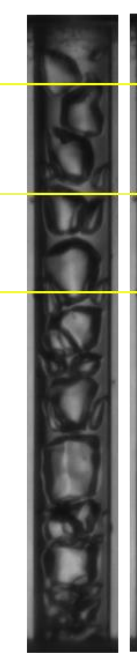

(j)

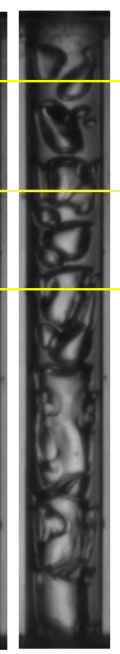

(k)

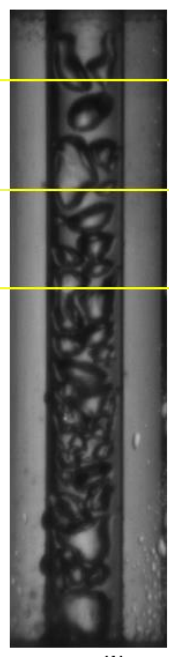

(I)

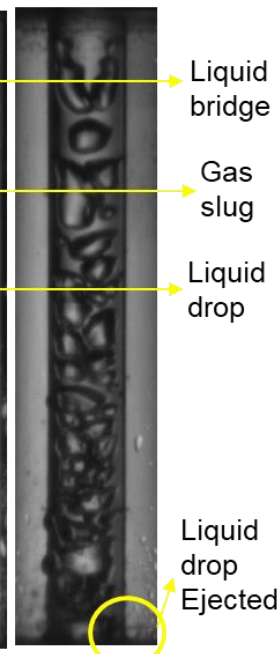

(m)

Figure 2 Two phase flow regimes for $7.3 \mathrm{mPas}$ liquid at a GLR of (a) $13.2 \%$ and $\mathrm{t}=0$ (b) $13.2 \%$ and $\mathrm{t}=219 \mathrm{~ms}$ (c) $13.2 \%$ and $\mathrm{t}=287 \mathrm{~ms}$ (d) $6.17 \%$ and $\mathrm{t}=0$ (e) $6.17 \%$ and $\mathrm{t}=34 \mathrm{~ms}$ (f) $6.17 \%$ and $\mathrm{t}=76 \mathrm{~ms}(\mathrm{~g}) 3.76 \%$ and $\mathrm{t}=0 \mathrm{~ms}(\mathrm{~h})$ $3.76 \%$ and $\mathrm{t}=24 \mathrm{~ms}$ (i) $3.76 \%$ and $\mathrm{t}=62 \mathrm{~ms}(\mathrm{j}) 2.1 \%$ and $\mathrm{t}=0 \mathrm{~ms}(\mathrm{k}) 2.1 \%$ and $\mathrm{t}=144 \mathrm{~ms}(\mathrm{l}) 0.94 \%$ and $\mathrm{t}=0 \mathrm{~ms}(\mathrm{k})$ $0.94 \%$ and $\mathrm{t}=3 \mathrm{~ms}$

The two-phase flow structures observed with the liquid of viscosity $42 \mathrm{mPa}$-s are shown in Figure 3. At the highest GLR of $17.23 \%$, an annular two-phase flow structure was observed like in the previous liquid. The formation of a liquid bridge was also observed at several time instants as shown in Figure 3(b). When the GLR was decreased to $7.48 \%$, liquid bridge occurred at many locations inside the mixing chamber. With time, these liquid bridges disappear due to coalescence of gas slugs as shown in Figure 3(c-e). A further decrease in GLR to $4.47 \%$ led to formation of gas slugs closer to the top of the mixing chamber. These slugs start to coalesce as they move downstream towards the exit orifice as shown in Figure $3(\mathrm{f}-\mathrm{g})$. At lower GLRs of $2.49 \%$ and $1.12 \%$, a bubbly flow regime was observed near the top part of the mixing chamber. The gas bubbles coalesce into slugs as they move downstream towards the orifice. Also, there were a few instances at which the gas was not injected into the first and second rows of gas injection holes. This phenomenon was previously observed and stated by Stahle et al. [9] and they attributed it to the negative pressure gradient in the liquid flow, which allows the gas injection at the lower injection holes where the pressure was low. In this study, gas injection was missing even from some of the holes downstream and was observed to be asymmetric as shown in Figure $3(\mathrm{~h}-\mathrm{m})$. Further investigation is required to find the reason for this kind of phenomenon. From the two-phase flow structure observations, it can be concluded that annual flow regime is predominant at higher GLRs for both the liquids while gas in the two-phase flow turns into slugs and bubbles at lower GLRs. With an increase in viscosity, there was a decrease in liquid flow rate due to which there was an increase in size of the gas bubbles. This helped in the transition from slug flow regime to annular regime or conversion of gas bubbles into gas slugs inside the mixing chamber even at the same GLR as it moved near the exit orifice. 


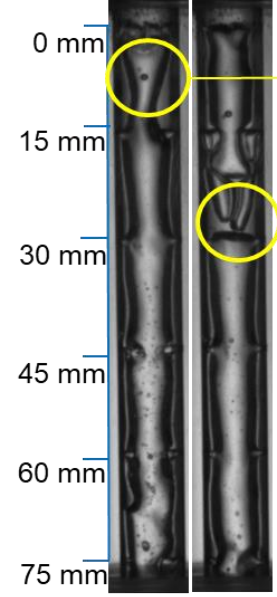

(a) (b)

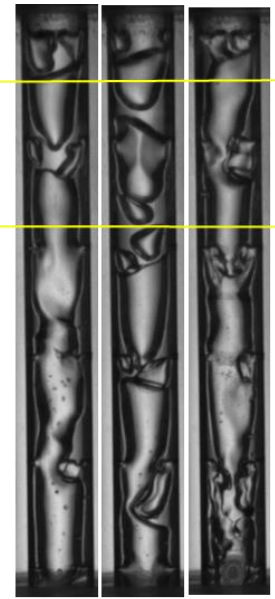

(c) (d) (e)

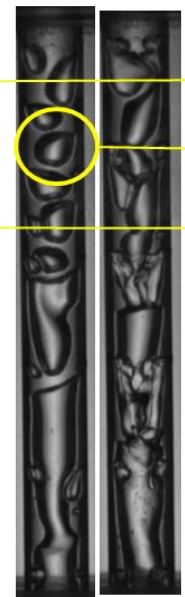

(f)

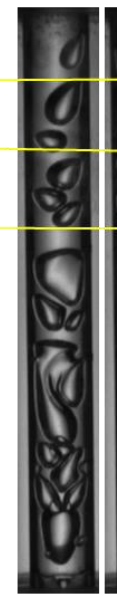

(h)

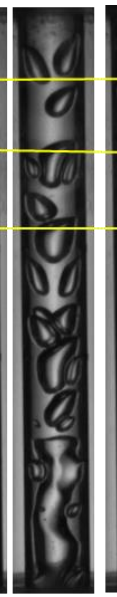

(i)

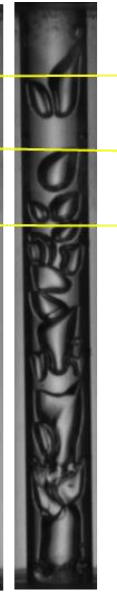

(j)

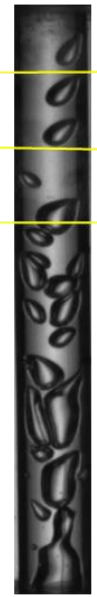

(k)

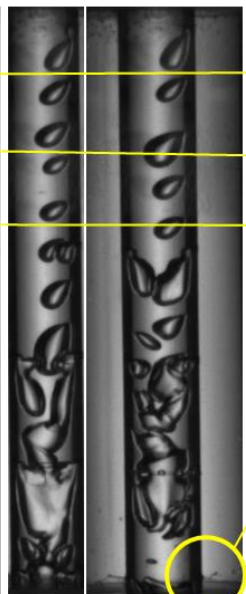

(I) (m)

Figure 3. Two phase flow regimes for $42.05 \mathrm{mPas}$ liquid at a GLR of (a) $17.23 \%$ and $\mathrm{t}=0$ (b) $17.23 \%$ and $\mathrm{t}=27 \mathrm{~ms}$ (c) $7.48 \%$ and $\mathrm{t}=0 \mathrm{~ms}$ (d) $7.48 \%$ and $\mathrm{t}=17 \mathrm{~ms}$ (e) $7.48 \%$ and $\mathrm{t}=47 \mathrm{~ms}$ (f) $4.47 \%$ and $\mathrm{t}=0 \mathrm{~ms}(\mathrm{~g})$ $4.47 \%$ and $t=30 \mathrm{~ms}$ (h) $2.49 \%$ and $\mathrm{t}=0 \mathrm{~ms}$ (i) $2.49 \%$ and $\mathrm{t}=151 \mathrm{~ms}$ (j) $2.49 \%$ and $\mathrm{t}=208 \mathrm{~ms}$ (k) $1.12 \%$ and $\mathrm{t}=0 \mathrm{~ms}(\mathrm{l}) 1.12 \%$ and $\mathrm{t}=200 \mathrm{~ms}(\mathrm{k}) 1.12 \%$ and $\mathrm{t}=242 \mathrm{~ms}$

Evaluation of spray unsteadiness: To study the effect of internal two-phase flow on the external spray characteristics, the variation of the average spray cone angle (of 50 images, corresponding to a time of $2.2 \mathrm{~ms}$ ) was studied. These variations in spray cone angle for different GLRs for the two liquids are shown in Figure 4. The variations were correlated with the observed two-phase flow regime in the mixing chamber. As discussed earlier, annual flow regime was predominant at higher GLRs for both the liquids while gas in the two-phase flow turned into slugs and bubbles at lower GLRs. Also, two different flow regimes occurred even for a same GLR. This resulted in the variation of spray cone angle and hence the unsteadiness. At lower GLRs these variations tend to increase as there are more variations in the internal flow structure from time to time. A further detailed investigation is required to correlate temporal variations of internal flow with external flow characteristics.

To quantify the unsteadiness in the spray, the coefficient of variation (COV) of the spray cone angle was calculated by taking the ratio of the standard deviation in cone angle to the mean value of cone angle. The variation of COV with GLR for both the liquids is shown in Figure 5. From the values, it can be seen that at high GLRs, which correspond to annular flow regime, COV values are very small. Hence it can be inferred that spray is more stable in the annular flow regime. With decrease in GLR, the COV value was found to increase as a result of two phase flow transitions from annular flow to slug flow. When these gas slugs are injected through the exit orifice, a pulsating spray was found to be obtained, which also increases the COV. The COV attained a maximum value when the two-phase flow regime was a slug flow. The spray became stable again and a decrease in COV was observed for the $7.3 \mathrm{mPas}$ viscosity liquid in the bubbly flow regime. From the spray structure images of $42 \mathrm{mPas}$ high viscosity liquid, it was observed that the atomization was poor, which resulted in a very low spray cone angle at low GLRs with intact liquid jet. The decrease of COV at low GLR was not observed for the liquid with higher viscosity since there was no formation of bubbly flow regime. 


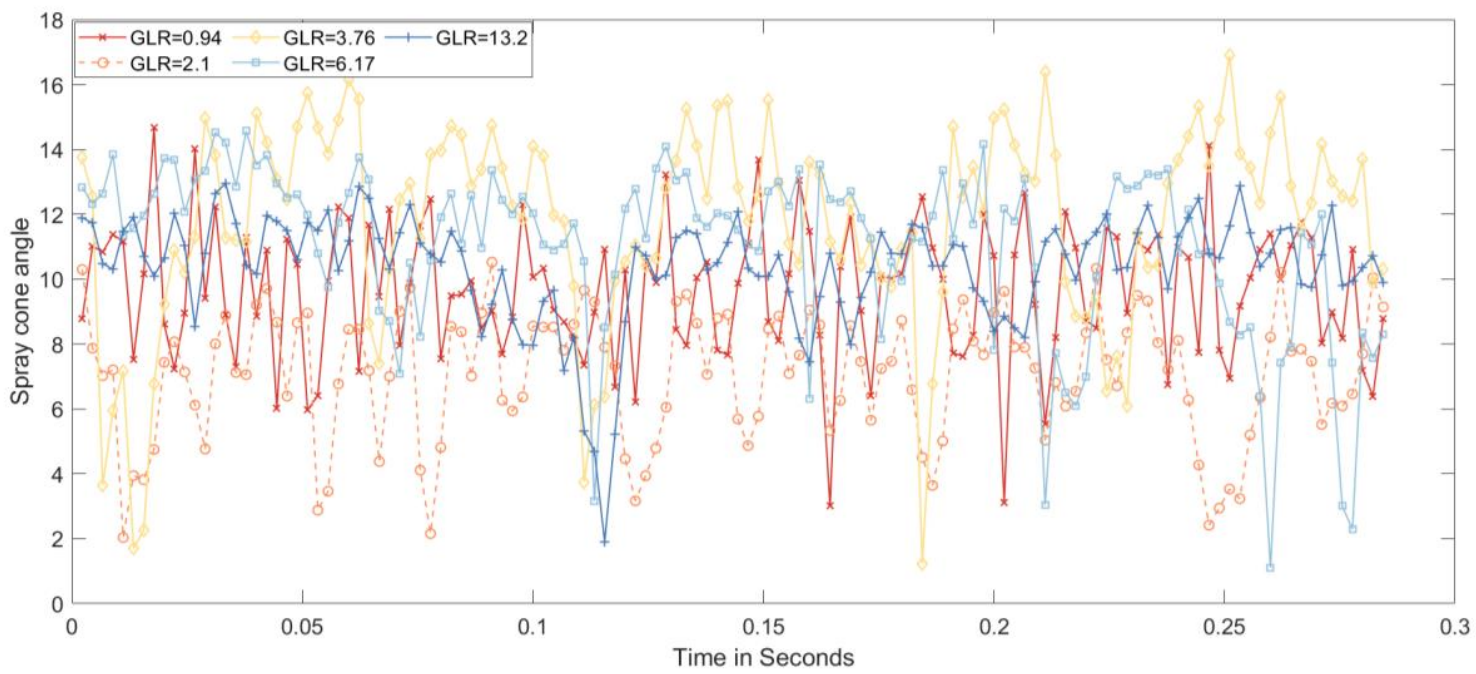

(a)

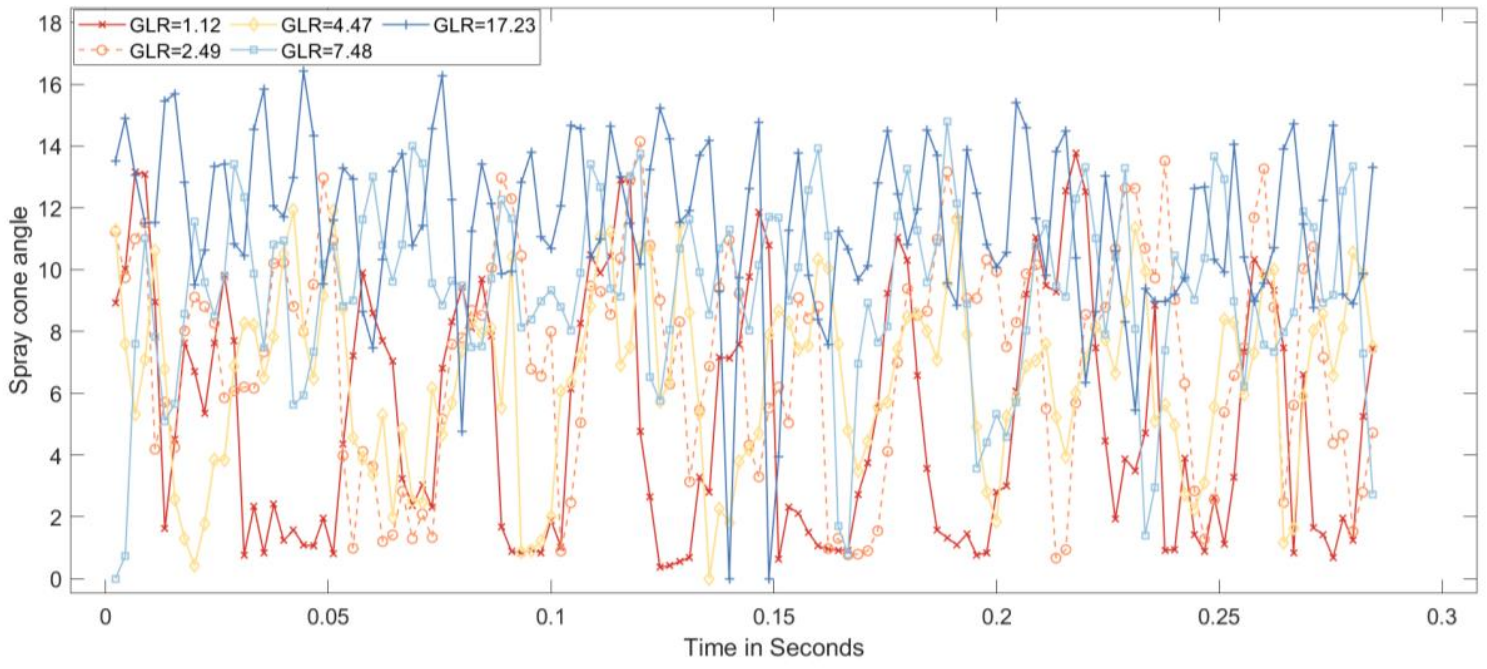

(b)

Figure 4. Spray Cone angle variation at different GLRs for (a) liquid of viscosity $7.3 \mathrm{mPa}-\mathrm{s}$ (b) liquid of viscosity $42.05 \mathrm{mPa}-\mathrm{s}$

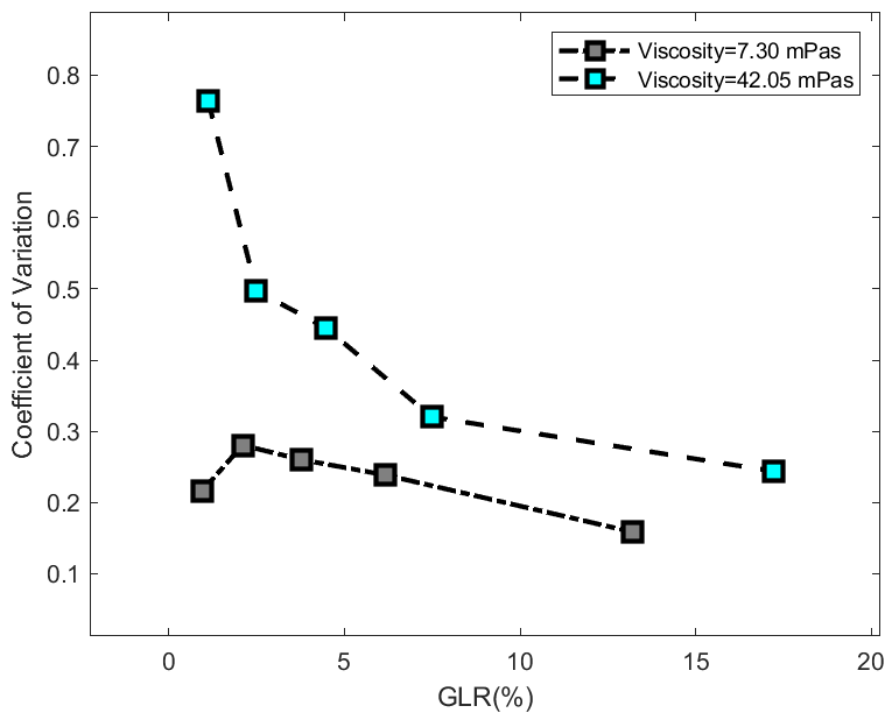

Figure 5. COV values at different GLRs studied for different liquid viscosities 


\section{Summary}

Spray unsteadiness in an effervescent atomizer was characterized by finding the coefficient of variation of the spray cone angle. The phenomenon of formation of different two-phase flow regimes was observed and correlated with the spray unsteadiness for different GLR values. It was observed that the spray was more stable at annular flow regime compared to bubbly flow regime and slug regime. The maximum COV was obtained for the slug flow regimes, where the spray was found to have highest instability. Hence for improving the stability of the effervescent atomizer, the two phase flow regime must be either an annular or a bubbly regime. Though the bubbly flow regimes for higher viscosity liquid showed smaller variation in spray cone angle, the atomization was observed to be inferior with intact liquid jet. This was observed to be the result of coalescence of bubbles into slugs as it moved near the exit orifice. A further detailed investigation is needed to correlate the temporal variation in the two-phase flow with the spray characteristics.

\section{Acknowledgement}

The authors acknowledge the support for the work from SERB India under the project CRG/2018/001508.

\section{References}

[1] Fu, N., Xiao, J., Woo, M. W., and Chen, X. D., 2020, Frontiers in Spray Drying, CRC Press.

[2] Shishir, M. R. I., and Chen, W., 2017, "Trends of Spray Drying: A Critical Review on Drying of Fruit and Vegetable Juices," Trends Food Sci. Technol., 65, pp. 49-67.

[3] Anandharamakrishnan, C.; Ishwarya, S. P., 2015, Spray Drying Techniques for Food Ingredient Encapsulation-Wiley-Blackwell (2015).

[4] Santos, D., Maurício, A. C., Sencadas, V., Santos, J. D., Fernandes, M. H., and Gomes, P. S., 2018, "Spray Drying: An Overview," Biomater. - Phys. Chem. - New Ed.

[5] Lefebvre, A. H., and Mcdonell, V. G., 2017, Atomization and Sprays, Second Edition.

[6] Sovani, S. D., Sojka, P. E., and Lefebvre, A. H., 2001, "Effervescent Atomization," Prog. Energy Combust. Sci., 27(4), pp. 483-521.

[7] Buckner, H. N., and Sojka, P. E., 1991, "Effervescent Atomization of High-Viscosity Fluids: Part I. Newtonian Liquids," At. Sprays, 1(3).

[8] Avulapati, M. M., and Ravikrishna, R. V., 2012, "An Experimental Study on Effervescent Atomization of Bio-Oil Fuels," At. Sprays, 22(8), pp. 663-685.

[9] Stähle, P., Gaukel, V., and Schuchmann, H. P., 2015, "Investigation on the Applicability of the Effervescent Atomizer in Spray Drying of Foods: Influence of Liquid Viscosity on Nozzle Internal Two-Phase Flow and Spray Characteristics," J. Food Process Eng., 38(5), pp. 474-487.

[10] Mlkvik, M., Stähle, P., Schuchmann, H. P., Gaukel, V., Jedelsky, J., and Jicha, M., 2015, "TwinFluid Atomization of Viscous Liquids: The Effect of Atomizer Construction on Breakup Process, Spray Stability and Droplet Size," Int. J. Multiph. Flow, 77, pp. 19-31.

[11] Zaremba, M., Weiß, L., Malý, M., Wensing, M., Jedelský, J., and Jícha, M., 2017, "Low-Pressure Twin-Fluid Atomization: Effect of Mixing Process on Spray Formation," Int. J. Multiph. Flow, 89, pp. 277-289.

[12] Roesler, T. C., and Lefebvre, A. H., 1989, "Studies on Aerated-Liquid Atomization," Int. J. Turbo Jet Engines, 6(4), pp. 221-229.

[13] Roesler, T. C., 1989, "An Experimental Study of Aerated-Liquid Atomization."

[14] Liu, M., Duan, Y. F., and Zhang, T. N., 2010, "Evaluation of Effervescent Atomizer Internal Design on the Spray Unsteadiness Using a Phase/Doppler Particle Analyzer," Exp. Therm. Fluid Sci., 34(6), pp. 657-665.

[15] Liu, M., Duan, Y., Zhang, T., and Xu, Y., 2011, "Evaluation of Unsteadiness in Effervescent Sprays by Analysis of Droplet Arrival Statistics - The Influence of Fluids Properties and Atomizer Internal Design," Exp. Therm. Fluid Sci., 35(1), pp. 190-198.

[16] Stähle, P., Gaukel, V., and Schuchmann, H. P., 2015, "Influence of Feed Viscosity on the TwoPhase Flow inside the Exit Orifice of an Effervescent Atomizer and on Resulting Spray Characteristics," Food Res. Int., 77, pp. 55-62.

[17] Whitlow, J. D., and Lefebvre, A. H., 1993, "Effervescent Atomizer Operation and Spray Characteristics," At. Sprays, 3(2). 